\title{
SEXUAL DIMORPHISM IN MAXILLARY FIRST MOLAR AMONG NEPALESE POPULATION OF EASTERN NEPAL
}

Sanjib Kumar Sah ${ }^{1 *}$, Suman Pokhrel ${ }^{2}$, Sidarth Timsinha ${ }^{3}$ Umesh Kumar Mehta ${ }^{4}$, Raju Kumar Chaudhary ${ }^{5}$, Rajesh Kumar Shah ${ }^{6}$

\section{Affiliation}

1. Lecturer, Department of Anatomy, Birat Medical College and Teaching Hospital, Nepal

2. Lecturer, Department of Physiology, Birat Medical College and Teaching Hospital, Nepal

3. Associate Professor, Department of Forensic Medicine, Birat Medical College and Teaching Hospital, Nepal

4. Assistant Professor, Department of Anatomy, Birat Medical College and Teaching Hospital, Nepal

5. Assistant Professor, Department of Anatomy, Birat Medical College and Teaching Hospital, Nepal

6. Lecturer Department of Forensic Medicine, Birat Medical College and Teaching Hospital, Nepal

\section{ARTICLE INFO}

Received : 04 March, 2021

Accepted : 28 July, 2021

Published : 04 November 2021

(C) Authors retain copyright and grant the journal right of first publication with the work simultaneously licensed under Creative Commons Attribution License CC - BY 4.0 that allows others to share the work with an acknowledgment of the work's authorship and initial publication in this journal.

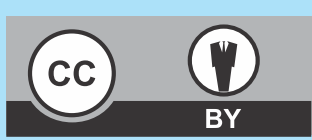

ORA 257

DOI: https://doi.org/10.3126/bjhs.v6i2.40331

* Corresponding Author

Dr. Sanjib Kumar Sah

Lecturer

Department of Anatomy

Birat Medical College \& Teaching Hospital, Morang, Nepal Email:drsanjibsah@gmail.com

ORCID: https://orcid.org/0000-0001-8361-5497

\section{ABSTRACT}

\section{Introduction}

Sexual dimorphism refers to differences in size, stature and appearance between male and female. It is a known fact that tooth crown is formed to full size in childhood even before eruption into oral cavity. The shape and size of the teeth permits an interesting dimension of study for sexual dimorphism, we aimed to delineate the sexual dimorphism by measuring the mesiodistal (MD) and buccolingual (BL) diameters of permanent maxillary first molar in Nepalese population of Eastern Nepal.

\section{Objectives}

The aim of this study was to evaluate the sexual dimorphism in maxillary first molar among Nepalese population of eastern Nepal

\section{Methodology}

100 participants of either sex (50 males \& 50 females) aged between 17 to 25 years were enrolled in the study. After thorough dental examination, impression of the maxillary arch was made and MD diameter and BL diameters were measured with the help of digital vernier caliper. A P value of $<0.05$ was considered as statistically significant.

\section{Result}

Sexual dimorphism was found in MD and BL diameters of maxillary first molar in males measuring higher than females. Right mesiodistal showed the highest sexual dimorphism, whereas right buccolingual showed the least.

\section{Conclusions}

This study confirms that permanent maxillary first molar shows significant sexual dimorphism, out of which mesiodistal measurement stands out to be the best parameter in Nepalese population of Eastern region.

\section{KEYWORDS}

Buccolingual, mesiodistal, molar teeth, sexual dimorphism

\section{Citation}

Sanjib Kumar Sah, Suman Pokhrel, Sidarth Timsinha, Umesh Kumar Mehta, Raju Kumar Chaudhary, Rajesh Kumar Shah. Sexual Dimorphism in Maxillary First Molar among Nepalese Population of Eastern Nepal BJHS 2021;6(2)15. 1492-1495. 


\section{Introduction}

Teeth are an excellent tissue material in living and non-living population for anthropological, genetic, odontologic and forensic investigations ${ }^{1}$. They exhibit the least turnover of natural structure and have strong resistance to decay and structural changes even long time after death. Durability in the face of fire and bacterial decomposition makes them invaluable for identification. ${ }^{1}$ Maxillary first molar are the first permanent teeth to erupt into the oral cavity at an average age of 6-7 years and are less likely to be impacted than canines. ${ }^{1}$ If the postcranial skeleton is intact, sex can be accurately determined in mature individuals. ${ }^{2,3}$ Sexual dimorphism refers to the differences in size, stature and appearance between male and female that can be applied to dental identification because no two dental arrangements are alike. ${ }^{4}$ Gender determination of skeletal remains is part of the archaeological, anthropological and medico-legal examinations. The only method that can give a totally accurate result is Deoxyribonucleic Acid technique but in many cases for several reasons it is quite difficult to perform because of its cost and time consumption. ${ }^{5,6}$ The study of the shape and size of the teeth permits an interesting dimension of study for sexual dimorphism; this is for the fact that tooth crown is formed to full size in childhood even before eruption into oral cavity. Sex differences in the dental indexes are assessed using univariate and multivariate statistic. ${ }^{7,8}$ This study is therefore a nobel attempt to study the sexual dimorphism in maxillary first molar teeth. This study also intends to find any changes in mesio-distal (MD) and buccolingual (BL) diameters between right and left side teeth in each gender. The result of the study could be a vital tool and may play a significant role in establishing the identity of an individual.

\section{METHODOLOGY}

This comparative cross-sectional study was conducted from $1^{\text {st }}$ August-31 $1^{\text {st }}$ November 2019 in the department of Dentistry and department of Anatomy, Birat Medical College \& Teaching Hospital (BMCTH), Morang, Tankisinwari, Nepal after the approval obtained from the Institutional Review Committee (IRC-PA-032/2076-77). 100 participants of either sex ( 50 males \& 50 females) aged between 17 to 25 years were enrolled in the study after confirming healthy status of gingiva and perionditium in dental out patient department. Convenient sampling techniques were used to choose the participants based on inclusion and exclusion criteria. In this study, subjects with a completely erupted healthy bilateral permanent maxillary first maxillary molars with healthy perionditium were included. Subjects with partially and ectopically erupted teeth, teeth showing physiologic or pathologic wear and tear (e.g.: attrition, abrasion, erosion), patients with dental \& occlusal abnormalities (rotation, crowding, occlusal disharmony etc.) were excluded from our study. Consented detailed proforma were obtained from the participants after explaining the entire procedures to ensure their voluntary participation. Irreversible hydrocolloid (alginate) material was used to make impressions of the maxillary arch and casts were poured instantly in type II dental stone to minimize dimensional changes. The BL and MD diameters of the permanent maxillary first molar were measured using digital vernier caliper on the study cast as shown in Figure 1 and Figure 2. The greatest distance on the occlusal surface between the perpendicular plane of mesial and distal surfaces of the crown of the tooth was taken as MD diameter, and the greatest distance between the perpendicular plane of buccal and lingual surfaces of the crown of the tooth was taken as BL diameter. The mean value of $\mathrm{MD}$ and $\mathrm{BL}$ diameters of male and female were used in the calculation of sexual dimorphism. Sexual dimorphisms in the right and left maxillary molar were calculated as:

Percentage of sexual dimorphism $=[(\mathrm{Xm} / \mathrm{Xf})-1] \times 100$ Where, $\mathrm{Xm}=$ mean of male tooth dimension, $\mathrm{Xf}=$ mean of female tooth dimension

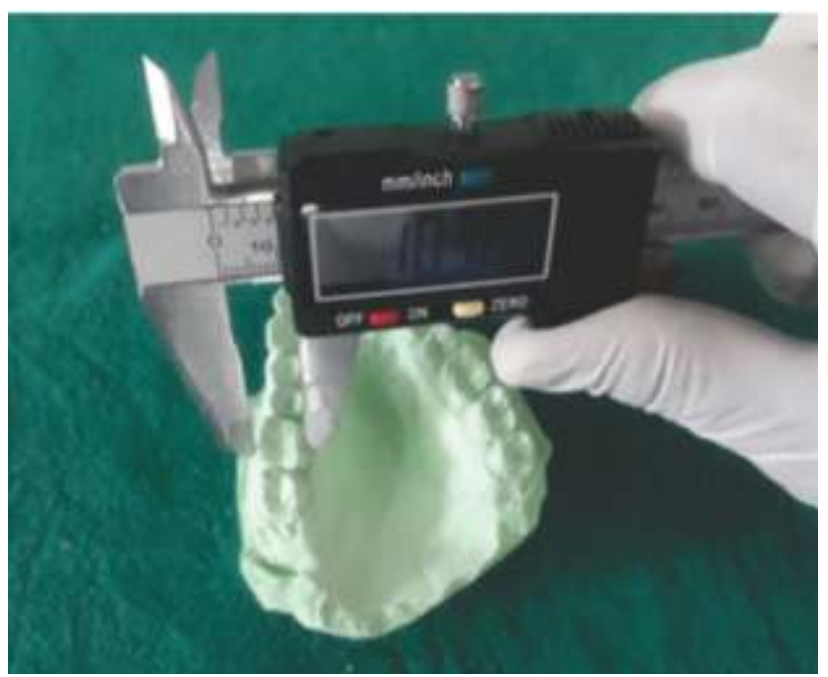

Figure 1: Showing bucco-lingual diameter

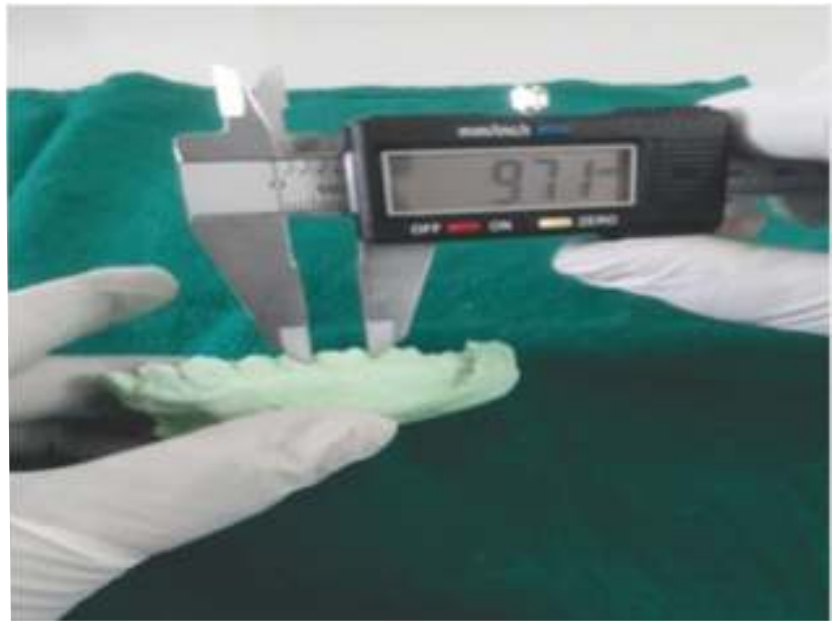

Figure 2 : Showing mesio-distal diameter

Measurements were tabulated on Excel sheet and analysis was done using Statistical Package for the Social Sciences (SPSS) version 25.0. Descriptive statistics and student's t-test were used as statistical tools to analyze the data. The p-value less than 0.05 were taken as statistically significant. 


\section{RESULTS}

On measuring $\mathrm{MD}$ and $\mathrm{BL}$ diameters for right and left first maxillary molar, it was found out that males had greater mean $\mathrm{MD}$ and $\mathrm{BL}$ diameters of first maxillary molar in comparison to females. However, the mean values of both $M D$ and $B L$ were not statistically significant (Table 1 ).

Table 1: Comparison between mesiodistal and buccolingual diameters in males and females.

\begin{tabular}{|c|c|c|c|c|}
\hline \multirow{2}{*}{ RMMD } & Gender & N & Mean \pm SD & p value \\
\cline { 2 - 4 } & Male & 50 & $10.64 \pm 0.54$ & \multirow{2}{*}{0.78} \\
\hline \multirow{2}{*}{ RMBL } & Female & 50 & $10.11 \pm 0.58$ & \\
\cline { 2 - 4 } & Male & 50 & $10.93 \pm 0.37$ & \multirow{2}{*}{0.62} \\
\hline \multirow{2}{*}{ LMMD } & Memale & 50 & $10.48 \pm 0.64$ & \\
\cline { 2 - 4 } & Memale & 50 & $10.53 \pm 0.44$ & \multirow{2}{*}{0.70} \\
\hline \multirow{2}{*}{ LMBL } & Male & 50 & $10.08 \pm 0.81$ & \\
\cline { 2 - 4 } & Female & 50 & $10.91 \pm 0.47$ & \multirow{2}{*}{0.20} \\
\hline
\end{tabular}

RMMD = Right Maxillary Mesiodistal Diameter; RMBL= Right Maxillary Buccolingual Diameter; LMMD = Left Maxillary Mesiodistal Diameter; LMBL= Left Maxillary Buccolingual Diameter.

Our results also showed that MD diameters were less than $B L$ diameters in both the sexes. Sexual dimorphism was found out to be $4.29 \%$ and $4.40 \%$ for right and left buccolingual diameters of maxillary first molars respectively as compared to $5.24 \%$ and $4.46 \%$ for right and left mesiodistal diameters of the same teeth (Table 2).

Table 2: Sexual dimorphism in maxillary first molars
\begin{tabular}{|c|c|c|c|c|}
\hline Study cast & RMMD & RMBL & LMMD & LMBL \\
\hline $\begin{array}{c}\text { Sexual } \\
\text { Dimorphism (\%) }\end{array}$ & 5.24 & 4.29 & 4.46 & 4.40 \\
\hline
\end{tabular}

RMMD = Right Maxillary Mesiodistal Diameter; RMBL= Right Maxillary Buccolingual Diameter; LMMD = Left Maxillary Mesiodistal Diameter; $\mathrm{LMBL}=$ Left Maxillary Buccolingual Diameter.

Our study showed that both the mesiodistal and buccolingual dimensions of right-side tooth were greater than the left side although the result was not statistically significant (Table 3).

Table 3: Comparison of mean values of mesiodistal and buccolingual diameters of right and left side.

\begin{tabular}{|c|c|c|c|c|}
\hline \multirow{2}{*}{ MD } & Side & $\mathbf{N}$ & Mean \pm SD & p value \\
\hline \multirow{2}{*}{ RL } & Right & 100 & $10.63 \pm 0.56$ & \multirow{2}{*}{0.15} \\
\cline { 2 - 4 } & Left & 100 & $10.50 \pm 0.65$ & \\
\hline \multirow{2}{*}{ BL } & Right & 100 & $10.81 \pm 0.52$ & \multirow{2}{*}{0.35} \\
\cline { 2 - 4 } & Left & 100 & $10.73 \pm 0.63$ & \multirow{2}{*}{0.35} \\
\hline
\end{tabular}

On correlation between left and right mesiodistal diameters of maxillary molar and buccolingual dimensions of either side maxillary molar and found out that they were strongly associated (Table 4).

Table 4: Correlation between left and right mesiodistal and buccolingual dimension.

\begin{tabular}{|c|c|c|}
\hline & LMMD & LMBL \\
\hline RMMD & $\begin{array}{c}r=0.67 \\
p=0.001\end{array}$ & - \\
\hline \multirow{2}{*}{ RMBL } & - & $r=0.45$ \\
$p=0.001$ \\
\hline
\end{tabular}

\section{DISCUSSION}

Craniofacial morphology, pubis measurements, dental records, DNA analysis etc. are some of the basis for human sex determination. Out of the known parameters, odontometrics studies being simple, inexpensive, and easy to measure, it has gained the epitome of popularity. Dental records have proved its significance in providing durable evidence even in post mortem identification which makes it a reliable biological feature in sex differentiation. ${ }^{9}$ Many studies had been carried out in different population and had demonstrated that sexual dimorphism can be accurately assessed by using dental dimensions. ${ }^{10-13}$ Mesiodistal (MD) and buccolingual (BL) diameters of maxillary first molar were measured. The diameters of maxillary first molar were found to be higher in males than females which were in accordance with other studies. ${ }^{4-6,14}$ Environmental factors and genetics may have been the primary factors bringing this kind of variation between both sexes. This change may also be due toamelogenesis which occur for longer duration in males. The crown calcification finishing early in femalesrelative to males also may subserve the variation. However, MD and BL diameters, we observed in our study between two sexes were not statistically significant as it was shown on few other studies. ${ }^{15}$ This might be due to the genetic variation of population that we undertook in our study.

In our present study both MD and BL parameters of right sided teeth were higher as compared to left sided teeth in both sexes. In accordance to our results, Bhavasar et al., who conducted similar kind of study in Guajarati population of India also showed similar finding in which right sided teeth parameters were higher as compared to left sided teeth. ${ }^{16}$ Contrarily, our results were not in accordance with the results showed by Rai B et al. who found out that right buccolingual diameters of maxillary first molars to be smaller than the left ones. ${ }^{7}$ Another study done by Sonika V et al. on Haryana population of India also showed all the diameters of left teeth were significantly higher than the right sided parameters. ${ }^{17}$ This variation could be due to the dental asymmetry of left and right side teeth possessed by the study population. Also this variation may be acquired due to the maximum use of right-side teeth during mastication and grinding of food.

Sexual dimorphism percentage in our study was calculated by using the standard formula comprising mean diameter of 
teeth and found out to be $5.24 \%$ for right maxillary mesiodistal diameter, $4.29 \%$ for right maxillary buccolingual diameter, $4.46 \%$ for left maxillary mesiodistal diameter and $4.40 \%$ left maxillary buccolingual diameter, respectively. The mesiodistal diameters of maxillary first molars in the present study were found to exhibit greater sexual dimorphism than buccolingual diameters of the same teeth. Similar findings were noted in a study conducted on Guajarati population in where sexual dimorphism were best demonstrated by mesiodistal dimension. ${ }^{16}$ Another study done by Manav et al. also showed and concluded that MD measurements were better suited than BL dimensions for sex determinations when used independently. ${ }^{18}$ In contrast to our results, Sonika V et al., Sharma et al. and Garn et al. showed maximum sexual dimorphism on buccolingual dimensions than mesiodistal dimensions. ${ }^{17,19}$ Narang RS et alalso observed sexual dimorphism to be $7.4 \%$ and $6.3 \%$ for right and left bucco lingual dimensions of maxillary first molars. ${ }^{20}$

\section{CONCLUSION}

Odontometrics features of teeth may subserve utmost help in determination of sex. The $M D$ and $B L$ dimensions of maxillary molar in male are greater than those of females and right sided dimensions are greater than the counterparts. This study confirms that permanent maxillary first molar shows significant sexual dimorphism, out of which mesiodistal measurement stand out as the best parameter in Nepalese population of Eastern region.

\section{RECOMMENDATION}

Prospective longitudinal study increasing the number of study subject is recommended. Also, such studies could be conducted in multiple centers so that the findings can be generalized in large population.

\section{LIMITATION OF STUDY}

The study includes only patients attending dental OPD of single tertiary care hospital. Therefore, due to small sample size the finding of the study cannot be generalized in large population.

\section{ACKNOWLEDGEMENT}

I would like to express my deep gratitude to $\mathrm{Dr}$ Laxmi Chapagain, Lecturer in department of Dentisry, BMCTH for taking impression and cast preparation and Dr. Tara Kafle, Assistant Professor in department of Community Medicine, BMCTH for statistical guidance.

\section{REFERENCES}

1. Rai B, Anand CS. Gender determination by diagonal distances of teeth. J Bio Anthr.2007; 1: 1-4.https://print.ispub.com/api/0/ispubarticle/11991

2. RRai B, Jain RK, Duhan J, Dutta S, Dhattarwal S. Evidence of tooth in sex determination. An International Journal of Medico-Legal Update. 2004;4(4):119-26. PMID: 21841267

3. Kiesu, JA: Human adult odontometrics. In: The study of variation in adult tooth size. Cambridge University Press 1900.

4. Rai B, Jain KR, Duhan J, Dutta S, Dhattarwal KS. Importance of maxillary first molar for sex determination. Internet J Dent Sci.2007; 4: 2.http://ispub.com/IJDS/4/2/12470

5. Acharya $A B$, Manaki $S$. Univariate sex dimorphism in the Nepalese dentition and the use of discriminant functions in gender assessment. Forensic Sci Int. 2007; 173 910: 47- 56.PMID: 17320321 DOI: 10.1016/j.forsciint.2007.01.024

6. Rai B, Dhattarwal KS, Anand CS. Sex determination from tooth. Medico-Legal Update - An Inter J 2008; 8 (1): 3-5.https:// www. indmedica.com/journals. php?journalid=9\&issueid=130\&articleid= 1723\&action=article

7. Acharya $A B$, Manali $S$. Sex discrimination potential of bucco-lingual and mesio-distal dimensions. J Forensic Sci.2008; 53 (4): $790-2$. PMID: 18557797 DOI: 10.1111/j.1556-4029.2008.00778.x

8. Acharya $A B$, Mainali $S$. Are dental index useful in sex assessment? J ForenOdonto2008; 27 (2): 53-9.PMID: 22717790

9. Gupta J. and Daniel J. Crown size and arch width dimension as an indicator in gender determination for a Puducherry population. Journal of Forensic Dental Science, 2016; 8(3):120- 25. DOI: 10.4103/0975-1475.195105

10. Işcan MY, Kedici PS. Sexual variation in buccolingual dimensions in Turkish dentition. Forensic Sci Int. 2003; 37: 160-4.PMID: 14609652

11. Angadi PV, Hwmani S, Suddendra, P, Acharya A. Analysis of odontometric sexual dimorphism and sex assessment accuracy of the deciduous teeth. Am J PhysAnthropol. 2013; 48: 77-82.PMID: 23910859
12. Prabhu S, Acharya $A B$ () Odontometric sex assessment in Indians. Forensic Sci Int. 2009; 192: 129e1-5.PMID: 19744808

13. Zorba E, Moraitis K, Eliopoulos C, Spiliopoulou C. Sex determination in modern Greeks using diagonal measurements of molar teeth. Forensic Sci Int. 2012; 217: 19-26.PMID: 22005548

14. Eboh DE. A dimorphic study of maxillary first molar crown dimensions of Urhobos in Abraka, South-Southern Nigeria. J MorpholSci 2012; 29 : 96-100.

15. Bhavasar, R., Patel, F., Soni, N., Patel, P., Shah, V. and Shah, P. Evaluation of sexual dimorphism by using permanent maxillary first molar in Gujarati population. Journal of Advanced Clinical \& Research Insights.2015; 2: 16-19. DOI: 10.15713/ins.jcri.35

16. Sonika V, Harshaminder K, Madhushankari GS, Sri Kennath JA. Sexual dimorphism in the permanent maxillary first molar: a study of the Haryana population (India). J Forensic Odontostomatol. 2011 Jul 1;29 (1): 37-43. PMID: 21841267; PMCID: PMC5734842.

17. Lakhanpal M, Gupta N, Rao NC, Vashisth S. Tooth dimension variations as a gender determinant in permanent maxillary teeth. J S M Dent 2013; 1: 2-5.https://www.jscimedcentral.com/ Dentistry/Articles/ dentistry-1-1014.php

18. Sharma S, Sharma S. Sexual Dimorphism in the Permanent Maxillary First Molar Teeth in the Rajasthan Population. J Mahatma Gandhi Univ Med Sci Tech 2020; 5(1): 4-8.DOI: 10.5005/jp-journals-10057-0119

19. Garn SM, Lewis $A B$, Kerewsky RS. Sexual dimorphism in the bucco lingual tooth diameter. J Dent Res 1966;45(6): 1819. DOI: 10.1177/ 00220345660450064301.

20. Narang RS, Manchanda AS, Arora PC, Kaur G. Sexual dimorphism in permanent 1st molar: A forensic tool. Indian J Compr Dent Care. 2012;2:224-7.https://www.ncbi.nlm.nih.gov/pmc/articles/PMC573 4842 / 